\title{
Trudności diagnostyczne w rowku głośni
} Diagnostic difficulties in sulcus vocalis

\section{Beata Miaśkiewicz ${ }^{1}$, Agata Szkiełkowska ${ }^{1,2}$}

${ }^{1}$ Klinika Audiologii i Foniatrii, Światowe Centrum Słuchu Instytutu Fizjologii i Patologii Słuchu, Warszawa/Kajetany

${ }^{2}$ Katedra Audiologii i Foniatrii, Uniwersytet Muzyczny im. Fryderyka Chopina, Warszawa

Adres autora: Beata Miaśkiewicz, Światowe Centrum Słuchu, Klinika Audiologii i Foniatrii, ul. Mokra 17, Kajetany, 05-830 Nadarzyn, e-mail: b.miaskiewicz@ifps.org.pl

\section{Streszczenie}

Wstęp: Terminowi rowek głośni funkcjonującemu w polskim piśmiennictwie odpowiadają w literaturze anglojęzycznej dwa terminy - sulcus vocalis i sulcus vergeture.

Celem pracy była analiza trudności w procesie diagnostycznym rowka głośni.

Materiał i metody: Materiał pracy stanowiła grupa 25 pacjentów z rowkiem głośni (15 kobiet i 10 mężczyzn). U 14 osób rozpoznano rowek o charakterze sulcus vergeture, a u 11 sulcus vocalis.

U pacjentów wykonano laryngowideostroboskopię, ocenę percepcyjną głosu (GRBAS) oraz wieloparametryczną akustyczną analizę głosu. Śródoperacyjnie, przy użyciu mikroskopu operacyjnego, wykonywano dokładną ocenę wizualną i palpacyjną fałdów głosowych.

Wyniki: W przedoperacyjnym badaniu wideolaryngostroboskopowym stwierdzono obecność poszerzonych naczyń krwionośnych u $36 \%$ osób z sulcus vergeture i u $54 \%$ z sulcus vocalis. Usztywnienie fałdu głosowego obserwowano u ponad połowy badanych. U prawie wszystkich chorych występowały zaburzenia fali śluzówkowej. U żadnego z pacjentów nie odnotowano pełnego zwarcia fonacyjnego. U 10 badanych w przedoperacyjnym badaniu stroboskopowym postawiono rozpoznanie rowka głośni typu vergeture, które zostało potwierdzone podczas mikrolaryngoskopii śródoperacyjnej. U pozostałych 15 chorych w przedoperacyjnym procesie diagnostycznym rozpoznano inne patologie fałdów głosowych i rozpoznania te zostały zweryfikowane podczas zabiegu.

Wnioski: 1. Rowek głośni jest patologią trudną do rozpoznania w badaniu wideolaryngostroboskopowym. Czasem dopiero mikrolaryngoskopia śródoperacyjna pozwala postawić ostateczną diagnozę; 2. Większe trudności diagnostyczne występują w przypadku sulcus vocalis; 3 . Trudności w postawieniu przedoperacyjnego rozpoznania pogłębia wspótistnienie z rowkiem innych patologii fałdów głosowych.

Słowa kluczowe: afonia $\bullet$ apraksja $\bullet$ dysfonia

\section{Abstract}

Summary: The term sulcus is used to describe two benign pathologies of the vocal folds- sulcus vergeture and sulcus vocalis.

Aim: The aim of the study is to assess difficulties in diagnostic process of sulcus.

Material and methods: Material of the study consisted of 25 patients with sulcus (15 women and 10 men). There were 14 cases of sulcus vergeture and 11 of sulcus vocalis.

All patients underwent videolaryngostroboscopy, perceptual voice assessment (GRBAS) and objective acoustic voice analysis. Accurate vocal folds examination was made under operative microlaryngoscopy.

Results: In preoperative videostroboscopy capillary ectasis was detected in 35\% patients with sulcus vergeture and 54\% subjects with sulcus vocalis. Over a half of studied group showed mucosal stiffness. In most of patients mucosal wave abnormalities were observed. Regarding glottis closure, all patient showed variable glottis chink. 
Based on findings from videolaryngostroboscopy sulcus vergeture was diagnosed in 10 patients, and was confirmed during microlaryngoscopy. In 15 subjects other vocal fold pathologies were diagnosed preoperatively, then verified and not confirmed during surgery.

Conclusions: 1. Detection of sulcus are difficult even in videolaryngostroboscopy. Microlaryngoscopy allows accurate diagnosis; 2. More diagnostic difficulties are encountered with sulcus vocalis; 3. Difficulties in making a preoperative diagnosis of sulcus are deepened by the coexistence of other pathologies of the vocal folds.

Key words: aphonia $\bullet$ apraxia $\bullet$ dysphonia

\section{Wstęp}

Terminowi rowek głośni funkcjonującemu w polskim piśmiennictwie odpowiadają w literaturze anglojęzycznej dwa terminy - sulcus vocalis $i$ sulcus vergeture. Te dwie patologie, charakteryzujące się penetracją nabłonka powierzchniowego fałdu głosowego w głąb struktury fałdu z jego przyrośnięciem do więzadła głosowego czy nawet włókien mięśnia głosowego, rozróżnił Bouchayer, słynny francuski fonochirurg. Sulcus vergeture jest to podłużne wklęśnięcie atroficznego nabłonka wzdłuż wolnego brzegu fałdu głosowego, natomiast sulcus vocalis jest zagłębieniem na górnej powierzchni fałdu głosowego w postaci kieszeni wysłanej hiperkeratotycznym nabłonkiem [1,2]

Etiologia schorzenia jest przedmiotem toczących się debat. Część autorów uważa, że rowek głośni jest schorzeniem wrodzonym, zwłaszcza gdy towarzyszą mu inne patologie, takie jak otwarta cysta epidermoidalna (ang. open epidermoidal cyst), mostek śluzówkowy (ang. mucosal bridge), czy też zaburzenia głosu utrzymują się od wczesnego dzieciństwa [1-4]. U części osób zaburzenia głosu pojawiają się jednak w życiu dorosłym i wiążą się z konkretnymi sytuacjami, jak intubacja do zabiegu w znieczuleniu ogólnym, wylew krwawy do fałdu głosowego czy przewlekła choroba refluksowa. Pacjenci z rowkiem głośni najczęściej zgłaszają chrypkę o różnym stopniu nasilenia, zmniejszenie intensywności głosu, podwyższenie głosu, szczególnie zauważalne u mężczyzn, męczliwość i załamywanie głosu po dłuższych wysiłkach głosowych, obecność napięcia czy przerw w głosie. W badaniu wideostroboskopowym krtani zwykle obserwuje się obecność łukowato wklęśniętego wolnego brzegu fałdu głosowego jedno- lub obustronnie, różnego stopnia ograniczenie lub brak fali śluzówkowej powodujące usztywnienie fałdu, brak pełnego zwarcia fonacyjnego. Czasami jest widoczne patologiczne unaczynienie fałdu głosowego w okolicy rowka. Drgania fałdów głosowych są nieregularne i niesymetryczne, a na poziomie nadgłośniowym obecne są cechy wtórnej hiperfunkcji $[1,2,5,6]$.

Metody leczenia są zróżnicowane i obejmują leczenie zachowawcze (rehabilitacja głosu, fizykoterapia) oraz chirurgiczne [1,2,6-11].

\section{Cel pracy}

Analiza trudności diagnostycznych w badaniu laryngowideostroboskopowym krtani u pacjentów z rowkiem głośni.

\section{Materiał i metody}

W latach 2009-2013 w Klinice Audiologii i Foniatrii Instytutu Fizjologii i Patologii Słuchu (IFPS) leczono

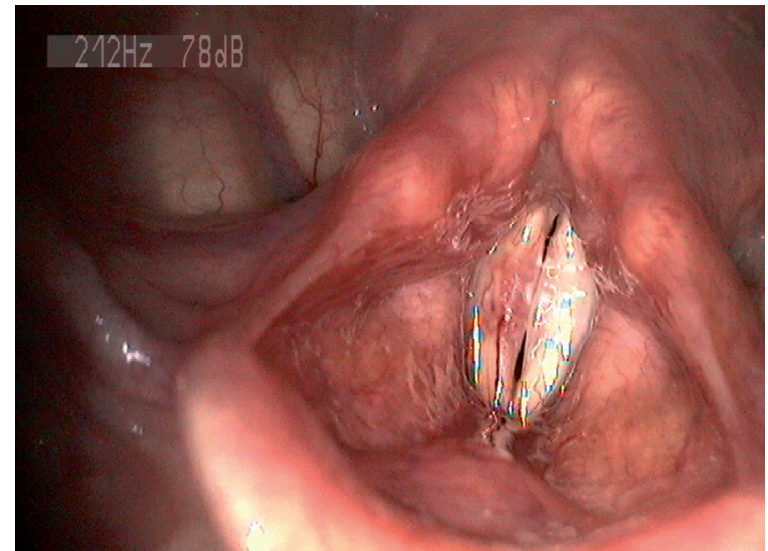

Rycina 1. Sulcus vocalis prawego fałdu głosowego

Figure 1. Sulcus vocalis of the right vocal fold

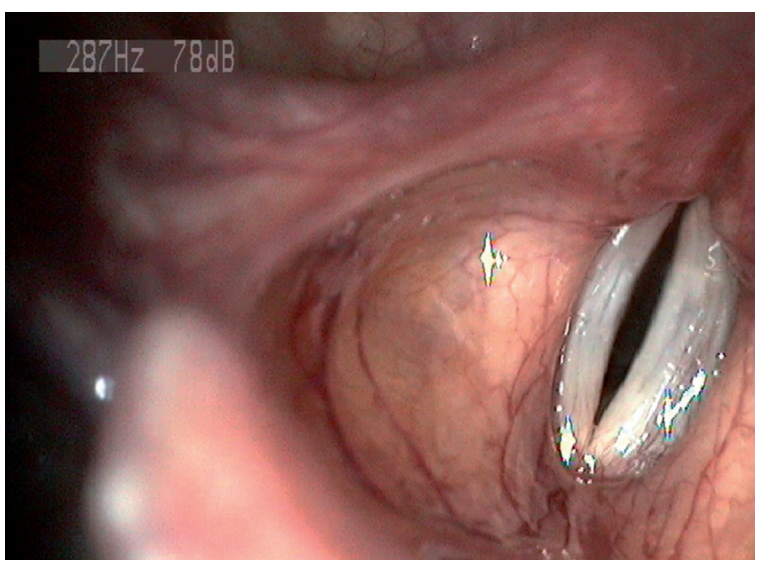

Rycina 2. Obustronna sulcus vergeture

Figure 2. Bilateral sulcus vergeture

chirurgicznie 25 pacjentów z rowkiem głośni (15 kobiet i 10 mężczyzn). Średnia wieku w badanej grupie wynosiła 41,5 lat. U 14 osób rozpoznano rowek o charakterze vergeture a u 11 sulcus vocalis (ryciny $1-3$ ). W 10 przypadkach rowek występował jednostronnie, w 15 obustronnie. Pacjenci zgłaszali przewlekłą chrypkę, osłabienie i męczliwość głosu, trudności w wypowiadaniu dłuższych fraz, zaniki głosu oraz dolegliwości bólowe w obrębie szyi i gardła podczas mówienia.

U wszystkich pacjentów przeprowadzono badanie laryngologiczne oraz foniatryczne, obejmujące laryngowideostroboskopię (LVS), ocenę percepcyjną głosu w skali GRBAS oraz wieloparametryczną akustyczną analizę głosu (MDVP). Ocenę LVS krtani przeprowadzono przy użyciu aparatury EndoStrob DX Xion 327. W badaniu oceniano ukształtowanie wolnego brzegu fałdu głosowego, charakter 


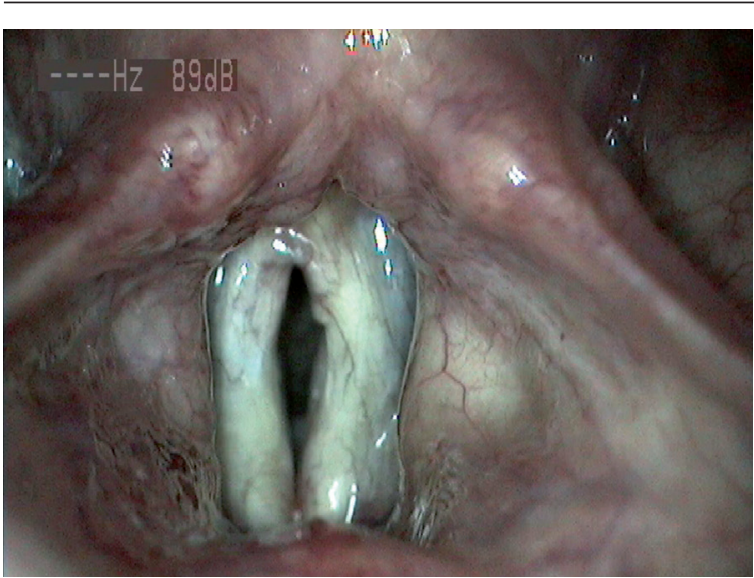

Rycina 3. Obustronna sulcus vergeture

Figure 3. Bilateral sulcus vergeture

Tabela 1. Ocena wybranych parametrów badania stroboskopowego fałdów głosowych w grupie badanej

Table 1. Assessment of chosen parameters of videostroboscopy in the studied group

\begin{tabular}{|c|c|c|}
\hline Parametr LVS & $\begin{array}{l}\text { Sulcus vergeture } \\
\qquad n=14\end{array}$ & $\begin{array}{l}\text { Sulcus vocalis } \\
\qquad n=11\end{array}$ \\
\hline \multicolumn{3}{|l|}{ Zwarcie fonacyjne } \\
\hline - pełne & 0 & 0 \\
\hline $\begin{array}{l}\text { - owalna szpara } \\
\text { fonacyjna }\end{array}$ & 5 & 1 \\
\hline $\begin{array}{l}\text { - brak zwarcia na całej } \\
\text { długości }\end{array}$ & 6 & 1 \\
\hline $\begin{array}{l}\text { - brak zwarcia } \\
\text { w odcinku tylnym }\end{array}$ & 2 & 3 \\
\hline - nieregularne & 1 & 6 \\
\hline \multicolumn{3}{|l|}{ Fala śluzówkowa } \\
\hline - prawidłowa & 1 & 0 \\
\hline - słabo zaznaczona & 8 & 7 \\
\hline - brak & 5 & 4 \\
\hline \multicolumn{3}{|l|}{$\begin{array}{l}\text { Usztywnienie fałdu } \\
\text { głosowego }\end{array}$} \\
\hline - brak & 4 & 4 \\
\hline - obecne & 10 & 7 \\
\hline \multicolumn{3}{|l|}{$\begin{array}{l}\text { Poszerzone } \\
\text { patologicznie naczynia }\end{array}$} \\
\hline - brak & 9 & 5 \\
\hline - obecne & 5 & 6 \\
\hline
\end{tabular}

zwarcia fałdów głosowych podczas fonacji, falę śluzówkową, symetrię, regularność i amplitudę drgań, obecność kompresji nadgłośniowej oraz występowanie organicznych, przerostowych zmian w obrębie fałdów głosowych.

U wszystkich osób w badanej grupie zastosowano leczenie chirurgiczne, które było uzupełnione przed- i pooperacyjną rehabilitacją głosu. Śródoperacyjnie, przy użyciu mikroskopu operacyjnego o ogniskowej $400 \mathrm{~mm}$, wykonywano dokładną ocenę wizualną i palpacyjną fałdów głosowych za pomocą kleszczyków mikrochirurgicznych.

\section{Wyniki}

W przedoperacyjnym badaniu laryngowideostroboskopowym stwierdzono obecność poszerzonych naczyń krwionośnych u $36 \%$ osób z sulcus vergeture i u $54 \%$ z sulcus
Tabela 2. Wyniki przedoperacyjnego badania wideolaryngoskopowego i mikrolaryngoskopii śródoperacyjnej

Table 2. Results of the preoperative videolaryngostroboscope and intraoperative microlaryngoscope evaluation

\begin{tabular}{lcc}
\hline $\begin{array}{c}\text { Rodzaj patologii } \\
\text { fałdów głosowych }\end{array}$ & $\begin{array}{c}\text { Stroboskopia } \\
\text { przedoperacyjna }\end{array}$ & $\begin{array}{c}\text { Mikrolaryngoskopia } \\
\text { śródoperacyjna }\end{array}$ \\
\hline Sulcus vergeture & 10 & 14 \\
\hline Sulcus vocalis & 0 & 11 \\
\hline Blizna & 4 & Nie potwierdzono \\
\hline Cysta & 2 & Nie potwierdzono \\
\hline Atrofia & 2 & Nie potwierdzono \\
\hline $\begin{array}{l}\text { Podejrzenie } \\
\text { nieokreślonej } \\
\text { patologii w obrębie } \\
\text { fałdu głosowego }\end{array}$ & 2 & Stwierdzono rowek \\
\hline $\begin{array}{l}\text { Inne patologie } \\
\text { wspótistniejące } \\
\text { z rowkiem }\end{array}$ & 5 & 5 \\
\hline
\end{tabular}

vocalis (tabela 1). Usztywnienie fałdu głosowego obserwowano u $71 \%$ badanych z sulcus vergeture i u $63 \%$ z sulcus vocalis. U prawie wszystkich chorych występowały zaburzenia fali śluzówkowej, najczęściej w postaci osłabienia przesunięcia brzeżnego, co obserwowano w $57 \%$ przypadkach sulcus vergeture i $63 \%$ sulcus vocalis. U żadnego pacjenta nie odnotowano pełnego zwarcia fonacyjnego. W grupie $\mathrm{z}$ sulcus vergeture dominowały owalna szpara fonacyjna i całkowity brak zwarcia podczas fonacji (64\%). Natomiast u chorych $\mathrm{z}$ sulcus vocalis najczęściej obserwowano nieregularny kształt szpary głośni podczas fonacji (54\%).

U 10 badanych w przedoperacyjnym badaniu stroboskopowym postawiono rozpoznanie rowka głośni typu vergeture, które zostało potwierdzone podczas mikrolaryngoskopii śródoperacyjnej. U pozostałych 15 chorych w przedoperacyjnym procesie diagnostycznym rozpoznano inne patologie fałdów głosowych i rozpoznania te zostały zweryfikowane podczas zabiegu (tabela 2). U 4 osób z opisywaną w stroboskopii blizną fałdu głosowego nie potwierdzono rozpoznania w ocenie mikrolaryngoskopowej, natomiast stwierdzono obecność sulcus vergeture w 2 przypadkach i sulcus vocalis $\mathrm{w}$ kolejnych dwóch. $\mathrm{U} 2$ badanych osób z rozpoznaną przedoperacyjnie cystą podczas zabiegu zdiagnozowano ostatecznie sulcus vocalis. Natomiast w 2 przypadkach atrofii fałdów głosowych, w mikrolaryngoskopii rozpoznano sulcus vergeture. U 2 osób w przedoperacyjnej ocenie stroboskopowej obserwowano duże zaburzenia wibracji fałdów głosowych w postaci znacznego osłabienia lub zupełnego braku przesunięcia brzeżnego w środkowym segmencie fałdu, zmniejszenie amplitudy, usztywnienie fałdu, co sugerowało obecność rowka, lecz bez ewidentnych cech pozwalających na jego rozpoznanie. Podczas zabiegu rozpoznano u tych chorych sulcus vocalis. Pięć osób zostało zakwalifikowanych do zabiegu operacyjnego z powodu obrzęków Reinkego ( 2 chorych), guzków głosowych (1 chory) i fibrous mass (2 chorych). We wszystkich tych przypadkach podczas śródoperacyjnego badania palpacyjnego fałdów głosowych za pomocą kleszczyków mikrochirurgicznych rozpoznano sulcus vocalis. 


\section{Dyskusja}

Rowek głośni jest patologią fałdów głosowych dającą zaburzenia głosu o mniejszym lub większym stopniu nasilenia. Do foniatry zgłaszają się najczęściej młodzi dorośli, zazwyczaj pracujący głosem, u których w pewnym okresie życia pojawiły się po raz pierwszy lub nasiliły się obecne wcześniej, ale nieprzeszkadzające, problemy z głosem. Podstawowym foniatrycznym badaniem diagnostycznym jest stroboskopia, która pomimo obecności na rynku nowocześniejszych metod pozostaje nadal „złotym standardem” w ocenie czynności fałdów głosowych. W przypadku rowka głośni, jak to wynika z naszych obserwacji oraz innych prac dostępnych w piśmiennictwie, badanie stroboskopowe nie jest często wystarczające do rozpoznania tej patologii, choć doświadczony foniatra czy fonochirurg może podejrzewać sulcus vocalis czy sulcus vergeture $[1,2,5,6,12]$. Opisywane w przypadku rowka głośni zagłębienie na przyśrodkowym wolnym brzegu fałdu głosowego może występować także u pacjentów $\mathrm{z}$ innymi patologiami krtani, jak fizjologiczne starzenie się narządu głosu (presbylaryngis), porażenie fałdu głosowego czy też przewlekły refluks żołądkowo-przełykowy ( seudosulcus) [12]. Patologiczny rowek charakteryzuje się występowaniem wklęśniętego wolnego brzegu fałdu, zaburzeniem fizjologicznej struktury warstwowej budowy fałdu głosowego, owalną szparą głośni podczas fonacji oraz usztywnieniem fałdu [5]. Dla postawienia dokładnej diagnozy pomocna jest ocena dolnej powierzchni fałdu głosowego podczas mikrolaryngoskopii $[2,12]$. Czasami, gdy w stroboskopii obserwujemy nasilone zaburzenia wibracji fałdów głosowych, choć bez ewidentnej obecności rowka czy innej patologii, oraz jeżeli pacjent prezentuje duże zaburzenia głosu a efekty przedoperacyjnej rehabilitacji głosu są niezadowalające, można zakwalifikować go do mikrolaryngoskopii. Podczas tego zabiegu czasami rozpoznajemy rowek głośni, tak jak u 2 chorych w badanym materiale.

Występowanie poszerzonych patologicznie naczyń na górnej powierzchni fałdu często towarzyszy sulcus vocalis [2].
W badanej grupie chorych objaw ten stwierdzono w $44 \%$ przypadków, nieco częściej w sulcus vocalis. Ford uważa, że skupisko położonych powierzchownie, poszerzonych naczyń sugeruje zmianę patologiczną w obrębie fałdu i może wskazywać na obecność rowka głośni [3].

W wielu przypadkach rowek głośni może współistnieć $\mathrm{z}$ innymi patologiami fałdów głosowych. Bouchayer podaje, że najczęściej w rowkach wrodzonych spotyka się współistniejące cysty, a sulcus vocalis określa jako odmianę open epidermoid cyst $[1,2,4]$. W badanej grupie chorych patologie współistniejące z sulcus vocalis, jak guzki głosowe czy obrzęki Reinkego, były najprawdopodobniej wtórnym efektem długotrwałej nieprawidłowej emisji głosu i niekorzystnych mechanizmów kompensacyjnych. Natomiast masa włóknista może być formą zejściową pękniętej torbieli epidermoidalnej, co sugerowali w swoich pracach Bouchayer i wsp. czy Gray i wsp. [2,4].

Jak wynika z naszych obserwacji, największe trudności sprawia zdiagnozowanie sulcus vocalis, w przypadku której rozpoznawano najczęściej w badaniu przedoperacyjnym bliznę lub cystę fałdu głosowego bądź stwierdzano patologię w obrębie fałdu głosowego niejasnego pochodzenia. Wnikliwa ocena stroboskopowa w połączeniu $\mathrm{z}$ prezentowanymi przez pacjenta objawami klinicznymi oraz doświadczeniem osoby badającej pomagają w postawieniu właściwego rozpoznania przedoperacyjnego.

\section{Wnioski}

1. Rowek głośni jest patologią trudną do rozpoznania w badaniu laryngowideostroboskopowym. Czasem dopiero mikrolaryngoskopia śródoperacyjna pozwala postawić ostateczną diagnozę.

2. Większe trudności diagnostyczne obserwuje się w przypadku sulcus vocalis.

3. Trudności w postawieniu przedoperacyjnego rozpoznania pogłębia współistnienie $\mathrm{z}$ rowkiem innych patologii fałdów głosowych.

\section{Piśmiennictwo:}

1. Bouchayer M, Cornut G. Microsurgery for benign lesions of the vocal folds. Ear Nose Throat J, 1988; 67: 446-66.

2. Bouchayer M, Cornut G. Microsurgical treatment of benign vocal fold lesions: indications, techniques, results. Folia Phoniatr, 1992; 44: 155-84

3. Ford CN, Inagi K, Bless DM, Khidr A, Gilchrist KW. Sulcus vocalis: a rational analytical approach to diagnosis and management. Ann Otol Rhinol Laryngol, 1990; 105: 189-200.

4. Gray SD, Hammond E, Hanson DF. Benign pathologic responses of the larynx. Ann Otol Rhinol Laryngol, 1995; 104: 13-8.

5. Hirano M, Yoshida T, Tanaka S, Hibi S. Sulcus vocalis: functional aspects. Ann Otol Rhinol Laryngol, 1990; 99: 679-83.

6. Giovanni A, Chanteret C, Lagier A. Sulcus vocalis: a review. Eur Arch Otorhinolaryngol, 2007; 264: 337-44.

7. Pontes P, Belhau M. Treatment of sulcus vocalis: auditory perceptual and acoustical analysis of slicing mucosa surgical technique. J Voice, 1993; 7: 365-76.
8. Abitbol J, Abitbol P. Surgical management of nonneoplastic vocal fold lesions: laser versus cold knife. Curr Opin Otolaryngol Head Neck Surgery, 2000; 8: 514-23.

9. Remacle M, Lawson G, Evrard I, Degols JC, Jamart J. Microsurgery of sulcus vergeture with carbon dioxide laser and injectable collagen. Ann Otol Rhinol Laryngol, 2000; 109(2): $141-8$.

10. Matar N, Remacle M, Amousa K, Lawson G. CO2 laser digital scanning system and injectable collagen for the treatment of sulcus vocalis. Oper Tech Otolaryngol, Head Neck Surg, 2011; 22: $155-8$.

11. Yilmaz T. Sulcus vocalis: excision, primary suture and medialization laryngoplasty: personal experience with 44 cases. Eur Arch Otorhinolaryngol, 2012; 269: 2381-9.

12. Lim JY, Kim J, Choi SH, Kim KM, Kim YH i wsp. Sulcus configurations of vocal folds during phonation. Acta Oto-Laryngol, 2009; 129: 1127-35. 